\title{
Transition to practice for the new graduate NP: A checklist and guide to understanding next steps
}

\author{
Lindsay F. Davis,' Christine M. Colella, Kimberly K. Mullins \\ College of Nursing, University of Cincinnati, Cincinnati, Ohio, Uinted States
}

Received: February 2, 2021

DOI: $10.5430 /$ jnep.v11n8p88
Accepted: April 21, 2021

URL: https://doi.org/10.5430/jnep.v11n8p88

\begin{abstract}
The transition to practice for the newly graduated nurse practitioner requires multiple steps. While accessible through multiple outlets it is cumbersome to gather. This article outlines a singular resource of next steps for the new graduate outlining the process for a successful transition to professional practice. A time-oriented checklist of essential tasks to keep the new graduate organized can reduce stress and delay on their path to becoming a nurse practitioner.
\end{abstract}

Key Words: Transition to practice, New graduate, Nurse practitioner, Certification, Licensure, Contract negotiation

\section{INTRODUCTION}

Transition into nurse practitioner (NP) practice begins during the educational program. While this most clearly occurs in the clinical courses, content about this should also be in courses which focus more globally on the advanced practice role. For example, information on certification bodies, the process for licensure, intricacy of the hiring, and if needed, credentialing processes, should be a part of the core NP curriculum.

As NP students approach graduation, the number of specific actions to prepare for their move into the advanced practice role increase. Provision of a checklist of the many steps can assist the students. While the focus of this article is on NPs in the United States of America (USA), the process can be useful to students entering other advanced practice roles.

The new graduate NP must complete a number of essential steps to be able to enter professional practice and provide patient care. These steps include certification, licensure, interviewing, contract salary negotiation, and in some situations credentialing. It is first necessary to define each term and recognize what each step represents to foster a foundation of understanding for students.

Certification denotes competency indicating that the required education has been completed and the individual is proficient and is the first step that the new NP graduate must take to prepare for professional practice. ${ }^{[1,2]}$ Licensure acknowledges the NP's ability to provide care for a designated population and is established after certification is achieved. Interviewing and contract negotiation is a multifaceted process in which the new NP and the employer agree to specific terms associated with the position. Once the individual is hired by the employer, credentialing may take place which allows for the NP to treat patients within a healthcare organization (HCO) ${ }^{[3]}$ The procedure for certification, licensure, interviewing, contract salary negotiation, and credentialing have many components. Each of these actions require specific steps that must be completed before proceeding to the next. Understanding the process can be overwhelming for the new

\footnotetext{
*Correspondence: Lindsay F. Davis; Email: davis2lf@ucmail.uc.edu; Address: College of Nursing, University of Cincinnati, Cincinnati, Ohio, United States.
} 
NP graduate emphasizing the need to prepare the student during the educational program to reduce stress and create a smoother entrance into the workforce. This article describes a singular resource that outlines the process, rationale, and steps to successful transition to professional practice and a checklist (see Table 1) for new graduates in the USA which categorizes these steps and provides an organized approach to their completion.

Table 1. New Graduate Checklist: Transitioning to Professional Practice

\begin{tabular}{|c|c|}
\hline New & raduate Checklist: Transitioning to Professional Practice \\
\hline $6 \mathrm{mc}$ & hs prior to graduation \\
\hline$\square$ & Explore the job market and network with colleagues for employment opportunities of interest \\
\hline$\square$ & Consider joining professional organizations on the state or national level to remain up-to-date and connected \\
\hline $3 \mathrm{mc}$ & hs prior to graduation \\
\hline$\square$ & Prepare resume and consider professional references \\
\hline$\square$ & Research certification exam preparation courses and materials \\
\hline$\square$ & Compare certifying bodies and review the process for applying for certification through the organization \\
\hline$\square$ & If applicable, apply for RN licensure in the state in which NP licensure will be sought \\
\hline $1 \mathrm{mc}$ & h prior to graduation/post-graduation \\
\hline$\square$ & Select certifying body and begin the application process \\
\hline$\square$ & Enroll in review course and/or obtain exam preparation material \\
\hline$\square$ & Schedule certification examination date \\
\hline$\square$ & Request transcripts are sent to the state board of nursing once degree is conferred \\
\hline After & ertification is awarded \\
\hline$\square$ & Request exam results are sent directly to the board of nursing from the certifying body \\
\hline$\square$ & Begin process for NP licensure through respective state* \\
\hline$\square$ & Review scope of practice according to respective state law \\
\hline$\square$ & Apply for National Provider Identification (NPI) number \\
\hline$\square$ & Apply for Drug Enforcement Administration (DEA) number if required/necessary \\
\hline Appl & ng for a job \\
\hline$\square$ & Revise and update resume/CV \\
\hline$\square$ & Initiate job search through professional networking/organizations, internet search \\
\hline$\square$ & Identify standards in the region for salary and benefits in preparation for contract negotiation \\
\hline$\square$ & Establish individual expectations for work/life balance as part of contract negotiation \\
\hline
\end{tabular}

\section{Certification}

To be eligible to apply for certification, individuals must be able to provide evidence that they successfully completed a masters, post-masters, or doctorate degree in nursing from an accredited NP program using the documentation requirements of their particular certification body. ${ }^{[1,2]}$ Prior to sitting for examination, new graduates should be strongly encouraged to enroll in review courses specific to the population foci and practice type of the certification which they seek. While review courses are costly, investing in the tools, re- sources, and test taking strategies have demonstrated success for many individuals. Information on major review courses should be provided for students to enage interest.

Since a number of certifying bodies exist specific to each population focus and practice type (i.e. acute care vs. community based) students should be encouraged to explore the options to determine which best meets their needs. The criteria required for eligibility to test varies among each certifying body. Each state requires national certification with the exception of California, Kansas, and New York. ${ }^{[4]}$ Students 
should be reminded to designate which board of nursing (BON) should receive the results as each state board requires they be notified the applicant has passed directly from the credentialing body. Once the individual is nationally certified they can apply for licensure.

\section{LICENSURE}

As the new graduate prepares for pratice it is important that they understand the process of licensure. The BON will require the transcript from the educational institution demonstrating that the master's, post-master's certificate, or doctorate academic degree has been conferred. Students should understand that degree conferral may not be reflected immediately upon graduation and in some cases can take several weeks. Verification that the applicant has completed a pharmacology course that complies with the BON requirements may be required if not clear on the transcript. Documentation of additional courses related to the specific state laws surrounding the dispensing of medications may also be required for licensure. Most states require finger-printing and a background check as well and guidance on identifying local sources for these should be provided for students to reference.

\section{Practice authority}

Students should be reminded that practice authority is designated by the state BON and is defined as the nurse's ability to practice with or without physician oversight. ${ }^{[5]}$ Scope of practice is defined as the NP's role based on the population and practice setting. This may vary from state to state as each state has specific laws that delineate what the NP may do as an advanced practice nurse. It is important that students understand the practice authority of their state and are familiar with where to reference this information.

There are 26 states in the USA with full practice authority for the NP. Full practice authority means that the state practice and licensure laws permit all NPs to practice without any physician oversight. ${ }^{[4]}$ There are 12 states that have practice and licensure laws with reduced practice. This means that the law requires a career long collaborative agreement with a physician in order to practice or it limits the setting of one or more elements of NP practice. ${ }^{[5]}$ Finally, there are 12 states that have restricted practice. In these states, the state licensure laws require a career-long supervision, delegation, or management by a physician in order to provide patient care. This difference across boards of nursing requires each graduate to fully understand the scope of practice in their state. The new graduate is held to the state law as it addresses all areas of practice. It is the NP's responsibility to understand how the law affects one's practice but also what is expected in that state for their title, signature, continuing education (CE) requirements, and many other items. Students should be advised to look to the state board for specific information in order to practice safely and within the law. Another component of the practice designated by the state $\mathrm{BON}$ is prescriptive authority. This determines what the NP may prescribe as per the state laws.

After licensing by the BON, the next step in preparation for practice is applying for a National Provider Identifying (NPI) number. This is a Health Insurance Portability and Accountability Act (HIPAA) administrative simplification standard. ${ }^{[6]}$ The student should recognize this number is used to identify the provider across all health plans and health care clearing houses. This 10-digit number is defined as an intelligence free numeric. That means it does not carry any information about the state one practices in nor one's designation. Every provider must have one and securing one is free. This information can be accessed at the Center for Medicare and Medicaid services.

Another important designation a new NP may need is a drug enforcement administration (DEA) number. Once employment is secured, and there is an expectation to prescribe scheduled drugs, the new NP can then apply for a DEA number. This DEA number allows one to prescribe (if allowed by the state license) scheduled drugs. Through this number the DEA can track controlled substances since every prescription for a scheduled medication must have the prescriber's DEA number on the prescription. ${ }^{[7]}$ It is important to be familiar with not only the prescriptive laws of the state but also best practice guidelines for utilizing scheduled drugs appropriately. The utilization of statewide monitoring databases is an important tool. The DEA registration is costly and must be renewed every three years. Prescribing any scheduled medication without a DEA number is illegal.

\section{Professional organizations}

To truly practice professionally, a new NP should join their professional organization at the state and national level. Students should be aware they may often join at a reduced rate while still enrolled in an educational program. Being part of the state's advanced practice organization gives the student and new NP information regarding any changes to the practice and laws in the state. The NP must be knowledgeable regarding their state's practice act. Any change at the BON can directly affect daily practice and it is the NP's responsibility to be aware. This affiliation can also give voice to the new NP to affect change and policy in regards to the state practice act. Being part of a national professional organization informs the NP about the issues or changes regarding advanced practice nationally. It will enlighten and engage 
the individual to step up to a role that could influence health policy changes. They can use their voice to ask questions, share ideas, and highlight issues that could improve practice and patient outcomes.

\section{INTERVIEWING AND CONTRACT NEGOTI- ATIONS}

Interviewing for a new position typically involves several steps and students should be prepared for what to expect. An initial interview may take place by phone or in person. A second interview may include the providers, staff, and practice manager. If there are other NP's working in the practice, it is preferred that they participate in the interviewing of and answering questions from the candidate. Depending on the position and competition, on occasion, there may even be a third interview. Once an offer is extended, contract negotiation takes place. Although the initial interview may have been with the physicians or NPs in that practice, the contract negotiation is typically between the candidate and a business manager or human resources professional. The person conducting this aspect of the hiring process is charged with accomplishing the best business transaction and will often approach the discussion with an expectation that there will be some negotiation of contract terms.

Many times, registered nurse positions do not require contract negotiation, therefore it is often an unfamiliar skill for the new NP. However, negotiatiation is an expected aspect of the hiring process, even though it may seem foreign or uncomfortable. Students should understand negotiation is a professional conversation and avoid the assumption that the compensation package is already set. ${ }^{[8]}$ Buppert, a respected authority on NP contract negotiation, describes three "P's" of negotiation: Prepare, probe and propose. ${ }^{[9]}$ Preparation includes estimating the revenue or value the NP position will bring to the practice. Probing is the assessment of the practice's financial health to ensure that the position is secure. Proposing involves suggesting appropriate additions or changes to the contract, in a neutral non-emotional manner, to ensure it reflects what is deserved. The contract should not be signed until agreeable terms are met. Once signed, the contract is a binding legal agreement that the NP and practice will be expected to uphold. ${ }^{[10]}$ As Brown and Dolan indicate, the contract is not to guarantee a perfect match but rather to minimize conflict after hire. ${ }^{[11]}$

There are obvious components to contract negotiation such as salary, work schedule, and practice expectations. However, other items such as benefits, continuing education allowance, and non-compete clauses (also called a restricted covenant) are crucial to a desirable agreement. ${ }^{[12]}$ See Table 2 for more information regarding these and other considerations. Knowing the salary range for one's geographic area, years of practice, and specialty will provide evidence-based data

with which to evaluate and negotiate a contract. Compensation and benefit standards for practice location and specialty can be found in a number of ways and directing students to these resources may be helpful. The Bureau of Labor Statistics reports salary ranges specific to NPs. Other surveys, such as those by professional nursing organizations, for instance the AANP (The American Association of Nurse Practitioners), can offer more specific information by area or specialty. Forbes offers a comparison of salaries in every state. ${ }^{[13]}$ There are additional resources that explain the nuances of salary such as The Advanced Practice Education Associates blog "Salary and Job Outlook for Nurse Practitioners".[14] Introducing students to these materials will make them a stronger and better prepared candidate for this first job.

Buppert recommends 20 questions to ask a prospective employer regarding the practice and their expectations of the position. ${ }^{[12]}$ Likewise, students should be instructed that there are terms of a position that will be considered personal preference, or quality of life issues. Defining the value and the extent to which one is willing to compromise on work life balance is an important factor best determined before finalizing a contract. Faculty can assist students in these determinations by providing opportunities for guided reflection. One strategy is to ask students to consider questions such as: If the position involves commuting to a remote office several days a week would this impact quality of life? If starting a family in the future, would this change the perspective of travel time? If the position requires on-call time would the frequency, length of on-call times, and compensation be acceptable?

Starting a position with realistic goals and mutually agreeable terms is key to a well-functioning and long-term working relationship. The final contract should serve to define the expectations for both the employee and employer. Should there be components of the contract that cannot be agreed upon by both parties, the NP may find it wise to respectfully decline the position. It is meaningful to share with students that while it may be tempting to accept a 'so-so' offer, agreeing to something that is disappointing in the beginning may eventually become intolerable. There are practices that may renegotiate if requested, but they are not required to do so. 
Table 2. Considerations for Components of a Hiring Contract

\begin{tabular}{|c|c|}
\hline \multicolumn{2}{|c|}{ Considerations for Components of a Hiring Contract } \\
\hline Salary & $\begin{array}{l}\text { - Is the position salaried? Hourly? Productivity based? } \\
\text { - Know the salary range for geographic area and specialty. }\end{array}$ \\
\hline $\begin{array}{l}\text { Work Schedule/ } \\
\text { Practice Expectation }\end{array}$ & $\begin{array}{l}\text { - Full time or part-time position? } \\
\text { - Is there a set schedule or an expectation to work weekends? Is travel involved - Will one work at } \\
\text { multiple locations? } \\
\text { - How will performance be evaluated and by whom? }\end{array}$ \\
\hline Continuing Education & $\begin{array}{l}\text { - Is there a continuing education expectation beyond what is required for licensure and certification? } \\
\text { - Can one choose the type of continuing education or is there content approval required? } \\
\text { - Will there be funds available for continuing education? } \\
\text { o How much? How often? } \\
\text { - Are continuing education days provided? } \\
\text { o How many per year? } \\
\text { o Is this paid time off? }\end{array}$ \\
\hline $\begin{array}{l}\text { Productivity/ } \\
\text { Bonus }\end{array}$ & $\begin{array}{l}\text { - Is there an expected number of patients to be seen? } \\
\text { o If so, is there a policy for building ones patient population? } \\
\text { o How long are the appointment slots? } \\
\text { o Is there a grace period with the initial start allowing more time and fewer patients as the APRN } \\
\text { becomes acclimated? } \\
\text { - If productivity based, is there a 'penalty' if the expectation is not met? What is the expectation based } \\
\text { upon? } \\
\text { - Does the practice measure productivity in relative value units (RVU's)? } \\
\text { o What is the minimum RVU required of the position? } \\
\text { o Is there a Bonus for exceeding the minimum RVU's? }\end{array}$ \\
\hline Benefits & $\begin{array}{l}\text { - Is Health insurance offered? } \\
\text { - Is a DEA number required, and if so, does the practice pay the fee? } \\
\text { - Is there a retirement benefit? } \\
\text { o If a 401-K, is there a match and how much? } \\
\text { - Paid Vacation } \\
\text { o How many weeks per year? } \\
\text { o Does this increase over time and what is the maximum? } \\
\text { o Are there restrictions as to how/when it can be used? } \\
\text { - Is maternity/paternity time offered outside of FMLA and how much is offered/paid? } \\
\text { - Sick leave } \\
\text { o Generally, one day/month per year. } \\
\text { o Is this dedicated sick time or from a paid time off (PTO) bank } \\
\text { - Travel allowance } \\
\text { o If travel is required is there reimbursement for time/mileage? } \\
\text { - Paid continuing education/ professional organization memberships? }\end{array}$ \\
\hline $\begin{array}{l}\text { On-Call/hospital round } \\
\text { requirements }\end{array}$ & $\begin{array}{l}\text { - Is taking call required? } \\
\text { - How often and for what period of time? } \\
\text { - Is this considered part of the base salary or is there additional pay for on call time? } \\
\text { - Is there a back-up person on call? } \\
\text { - Is time off given after call? Example: Call on Saturday \& Sunday, Monday off. } \\
\text { - If call requires seeing patient in the clinic or hospital, is this reimbursed in addition to regular salary? }\end{array}$ \\
\hline Non-Compete clause & $\begin{array}{l}\text { - Does the contract have a non-competed clause? } \\
\text { - How long does it last after termination of the position? } \\
\text { - To what geographic area does it extend? }\end{array}$ \\
\hline
\end{tabular}




\section{Credentialing AND PRivileging}

Credentialing and privileging is the process that allows a provider to see and care for patients within a HCO. These processes are in place to validate that the provider meets at least the minimum requirements for providing competent and safe patient care. Credentialing is the verification of the applicant's qualifications and competence and occurs first in order to grant privileges. This includes verification of education, training, experience, licensure, and certification. ${ }^{[3]}$

Privileging defines the acceptable scope of practice for patient care within the institution. This is based on credentials and performance. Privileges granted within an institution may be more restrictive than the scope of practice defined by the state BON, but they cannot be more liberal. The organizations bylaws will guide and govern the process of acquiring and maintaining credentialing and privileges, as well as the acceptable patient care practices within the organization. There are multiple steps for these processes, specific documents that may be required, and time for the governing board to review and vote. Once privileges are granted, these remain active for a period of time, often two-year intervals, as long as the provider remains in compliance with the bylaws.

It may be reassuring for the new NP to know that typically, a clinical practice has an office manager or credentialer who oversees the maintenance of provider licensure, certifications, and privileging. This individual will guide the provider through the credentialing and privileging process. Nonetheless, faculty can provide an overview of the typical process prior to graduation. The first step of which is usually a precredentialing application. This will involve a questionnaire to determine that the applicant has a full and unrestricted license, or if there have been any disciplinary actions by a professional licensing board. Other questions included ascertain if there is a criminal history or previous malpractice claims. The applicant may be asked to submit a curriculum vitae (CV), proof of certification, or licensure. There is often opportunity to share an explanation should there be previous or current infractions in any of these areas. Students should be counseled that it is wise to be forthright with these answers since a thorough background check is part of this process. It is common practice for the $\mathrm{HCO}$ to hire a credentials verification organization (CVO) to validate background and qualifications as well as comparing actual findings to those the applicant reported. Once this is accepted, the next step may include a full application in which the applicant agrees to provisions outlined in the organizational bylaws.

Upon verification of credentialing, the process of assigning privileges takes place. The $\mathrm{HCO}$ will often have a form with sets of predefined privileges based on the type of provider and the environment in which they will be treating patients. The applicant completes the form requesting the privileges they feel appropriate to their role. It is the responsibility of the NP to ensure the privileges requested are consistent with their scope of practice. Peer recommendations are required to speak to the NP's ability, professionalism, and confirm that the privileges requested are consistent with the individual's scope of practice. This information will go before the $\mathrm{HCO}$ medical board for consideration and the privileges will either be denied or approved. Should they be denied, rationale is provided and the bylaws should outline the appeal process.

The new NP should be made aware that this process may take as little as a few weeks in a small system or in some cases several months. In larger institutions, such as an academic center, privileging applications may be reviewed in batches at a monthly medical board meeting. This can add to the waiting time of the applicant and is something to consider, particularly if the NP position requires seeing patients within the HCO regularly. Determining if it will be possible to see patients in another setting until privileges are granted may help prevent lost work time and revenue.

\section{Conclusion}

Obtaining certification, licensure, credentialing and privileging is an involved process for the new graduate. Engaging the student in this process prior to graduation is vital to help them stay on task and be prepared for their transition to the NP role. It is important to provide students with the information they need for a successful transition. Offering a tool which outlines specific steps will help students and new NP graduates feel organized as they bridge the gap to professional practice. This checklist and succinct summary of essential requirements will aid in keeping the new graduate on track providing ample time to organize and prepare essential documents. Ensuring a seamless transition from education to practice can reduce stress for the new NP allowing them to transfer their focus to this new professional role.

\section{Conflicts of InTEREST Disclosure}

The authors declare that there is no conflict of interest.

\section{REFERENCES}

[1] American Academy of Nurse Practitioners Certification Board. AANPCB family nurse practitioner adult-gerontology primary care nurse practitioner candidate handbook. American Academy of Nurse Practitioners Certification Board. 2020. Available from: https://www.aanpcert.org/resource/documents/AG 
NP $\% 20 F N P \% 20$ Candidate $\% 20$ Handbook.pdf

[2] American Nurses Credentialing Center. Certification general testing and renewal handbook. American Nurses Credentialing Center. 2017. Available from: https://www.nursingworld.org/ 4aae16/globalasse ts/certification/certification-policies/ancc-gener altestingrenewalrequirements4-1-2017_final.pdf

[3] The Joint Commission. Credentialing and privileging: Implementing a process. The Joint Commission. 2012. Available from: https://www.jointcommission.org/resources/news-and -multimedia/blogs/ambulatory-buzz/2012/03/guest-blo gger-virginia-mccollum-credentialing-and-privilegi ngimplementing-a-process/

[4] American Association of Nurse Practitioners. State practice environment. American Association of Nurse Practitioners. 2019. Available from: https://www .aanp.org/advocacy/state/st ate-practice-environment

[5] National Conference of State Legislatures, \& Association of State and Territorial Health Officials. Nurse practitioners overview. Scope of Practice Policy. 2021. Available from: http://scopeofpract icepolicy.org/practitioners/nurse-practitioners/

[6] Centers for Medicare and Medicaid Services. National provider identifier standard. Centers for Medicare and Medicaid Services. 2019. Available from: https ://www.cms.gov/Regulations-and-Guidance/Admi nistrative-Simplification/NationalProvIdentStand\# :
: text=The $\% 20$ National $\% 20$ Provider $\% 20$ Identifier $\% 20$ (NP I , for $\% 20$ covered $\% 20$ health $\% 20$ care $\% 20$ providers

[7] United States Drug Enforcement Administration. (n.d.). Drug scheduling. United States Drug Enforcement Administration. Available from: https://www.dea.gov/drug-scheduling

[8] Danielsen RD, Potenza AD, Onieal M. Negotiating the professional contract. Clinician Reviews. 2016; 26(12): 28.

[9] Buppert C. Nurse practitioner's business practice and legal guide. 5th ed. Jones \& Bartlett Learning. 2014a.

[10] Buppert C. Terms of employment. The Journal for Nurse Practitioners. 2018; 14(8): 634-635. https://doi.org/10.1016/j.nurp ra.2018.06.003

[11] Brown L, Dolan C. Employment contracting basics for the nurse practitioner. The Journal for Nurse Practitioners. 2016; 12(2): e45-e51. https://doi.org/10.1016/j.nurpra.2015.11.026

[12] Buppert C. 20 questions to ask a prospective employer. Journal for Nurse Practitioners. 2014b; 10(1): 62-63. https ://doi .org/10.1 016/j.nurpra.2013.10.011

[13] DePietro A. Here's how much money nurse practitioners make in every state. Forbes. 2019. Available from: https : //www . forbes. com/sites/andrewdepietro/2019/1 1/19/nurse-practitioner-salary-state/\#4b632c5623cf

[14] Advanced Practice Education Associates. Salary and job outlook for nurse practitioners. Advanced Practice Education Associates. 2020. Available from: https://www.apea.com/blog/salary-and-j ob-outlook-for-nurse-practitioners 